\title{
HUBUNGAN KELELAHAN DENGAN KEMAMPUAN KERJA KARYAWAN BAGIAN HOUSEKEEPING HOTEL BINTANG TIGA DI DENPASAR
}

\author{
Ni Kadek Suastini ${ }^{1}$, I Nyoman Adiputra ${ }^{2}$ \\ Program Studi Pendidikan Dokter Fakultas Kedokteran Universitas Udayana ${ }^{1}$ \\ Bagian Ilmu Faal Fakultas Kedokteran Universitas Udayana ${ }^{2}$
}

\begin{abstract}
ABSTRAK
Kepariwisataan telah menjadi salah satu mesin kemajuan sosio-ekonomi utama untuk banyak negara. Banyaknya pengguna fasilitas hotel berbintang membuat para karyawan hotel lebih ekstra dalam menyiasati penataan hotel terutama pada karyawan housekeeping yang bekerja dengan mengutamakan kekuatan fisik sebagai pusat kegiatan yang berpengaruh pada kelelahan dan kemampuan kerja. Penelitian ini menganalisis hubungan tingkat kelelahan dengan kemampuan kerja. Penelitian dilakukan secara observasional (non eksperimental) dengan pendekatan analitik cross-sectional. Jumlah responden terdiri dari 31 orang yang terdiri dari karyawan bagian housekeeping hotel bintang tiga di Denpasar, dengan mengisi kuesioner Work Ability Index dan kuesioner 30 item of rating scale dari Japan Association Industrial Health dan Industrial Fatigue Committee Research of Japan. Dari hasil penelitian terdapat rerata kelelahan 40,81 $\pm 9,35$. Sedangkan rerata kemampuan kerja $41,25 \pm 4,15$. Terdapat hubungan yang signifikan antara kelelahan dan kemampuan kerja dengan nilai $\mathrm{p}=0,011$ dan nilai $\mathrm{r}=-0,450$. Nilai $\mathrm{p}$ menunjukkan terdapat hubungan yang bermakna antara kelelahan dan kemampuan kerja, dan nilai $r$ menunjukkan adanya hubungan yang berlawanan arah antara kelelahan dan kemampuan kerja. Dapat disimpulkan bahwa terdapat hubungan antara kelelahan dengan kemampuan kerja karyawan hotel pada bagian housekeeping. Untuk itu bagi pihak hotel perlu mengetahui skor kelelahan dan skor kemampuan kerja tiap individu untuk meningkatkan kemampuan kerja karyawannya khususnya yang bekerja di bidang fisik dan mental.

Kata kunci : kelelahan, kemampuan kerja, housekeeping
\end{abstract}

\section{CORRELATION OF FATIGUE AND WORK ABILITY IN 3-STAR HOTEL EMPLOYEES HOUSEKEEPING SECTION, DENPASAR.}

\begin{abstract}
Tourism has become one of the engines of socio-economic progress for many countries. The number of users star hotel facilities makes the hotel more extra employees in negotiating the arrangement of the hotel especially the housekeeping employees who work with emphasis on physical strength as the center of activities that affect the fatigue and employability. This study analyzed the correlation between fatigue and work ability. Research conducted observational (non-experimental) with a cross-sectional analytic
\end{abstract}


approach. The number of respondents consisted of 31 respondents consisting of employees of the housekeeping three stars hotel in Denpasar, to fill in the questionnaire Work Ability Index and the 30 item questionnaire rating scale of the Japan Association of Industrial Health and Industrial Fatigue Research Committee of Japan. From the research, there is $40.81 \pm 9.35$ mean of fatigue. While, the average of work ability is $41.25 \pm 4.15$. There is a significant relationship between the fatigue and the work ability with the value of $(p=$ $0.011)$ and values of $(r=-0,450)$. The $p$-value indicates there is a significant relationship between fatigue and work ability, the value of $r$ indicates the direction opposite relationship between fatigue and work ability. It can be concluded that there is a relationship between fatigue with the work ability of employees at the hotel housekeeping. For the hotel need to know the fatigue scores of each individual to improve the employees work especially those working in the field of physical and mental.

Keywords: fatigue, work ability, housekeeping

\section{PENDAHULUAN}

Kelelahan merupakan suatu mekanisme perlindungan tubuh agar tubuh terhindar dari kerusakan lebih lanjut sehingga diperlukan untuk beristirahat agar terjadi pemulihan (Susetyo, dkk., 2012). Prevalensi kelelahan pada pekerja di beberapa sektor bisa bervariasi antara 7$45 \%$ tergantung instrumen yang digunakan untuk mengukur (Vasconcelos, et al., 2011). Selain itu, kelelahan kerja terbukti memberikan kontribusi lebih dari $60 \%$ dalam kejadian kecelakaan di tempat kerja (Syahdianto, dkk., 2012). Kelelahan kerja dapat mengakibatkan keadaan seperti prestasi kerja menurun, badan terasa lemas, semangat kerja menurun dan diduga dapat menurunkan kemampuan kerja. Kemampuan kerja merupakan hasil interaksi antara pekerja dengan hasil karyanya (Ilmarinen, 2012). Kemampuan kerja dideskripsikan sebagai sebuah rumah yang memiliki empat lantai dengan tingkat yang berbeda. Lantai dasar disebut kesehatan dan kapasitas fungsional yang menggabungkan kesehatan dengan dimensi fisik, mental dan fungsi sosial atau gaya hidup. Lantai kedua terdiri dari kompetensi, yang termasuk didalamnya pengetahuan dan keterampilan serta kebutuhan belajar seumur hidup. Lantai 
ketiga disusun oleh nilai, sikap, dan motivasi. Lantai keempat mencakup pekerjaan, komunitas kerja dan kepemimpinan, yang terdiri atas lingkungan kerja dan komponennya misalnya fisik, mental dan social (Fernandes, et al., 2013). Kelelahan dapat diukur secara subyektif dengan menggunakan kuisioner, 30 item self rating test dengan skala empat yang direkomendasikan oleh Japan Association Industrial Health dan Industrial Fatigue Committee Research of Japan dan dengan menggunakan work ability index (WAI) atau indeks kemampuan kerja untuk mengukur kemampuan kerja (HandariAdiputra, 2013).

\section{BAHAN DAN METODE}

Rencana penelitian ini menggunakan metode observasional (non eksperimental) dengan pendekatan analitik cross-sectional yang dalam pelaksanaannya meliputi pengumpulan data, analisis, dan interpretasi dari data yang telah diperoleh. Penelitian ini merupakan non eksperimental karena tidak dilakukan kontrol dan manipulasi variabel penelitian serta hanya melakukan pengambilan data dalam satu waktu. Pemilihan sampel dilakukan dengan teknik simple random sampling, dimana subjek yang memenuhi kriteria inklusi akan dipilih secara acak hingga jumlah sampel terpenuhi. Populasi target penelitian ini adalah karyawan hotel bintang tiga dan populasi terjangkau adalah karyawan hotel bintang tiga di Denpasar.

Bahan dan instrumen penelitian meliputi WAI (Work Ability Index), untuk mengukur kemampuan kerja karyawan, kuisioner 30 item of rating scale dari Japan Association Industrial Health dan Industrial Fatigue Committee Research of Japan untuk mengukur kelelahan, timbangan analog untuk mengukur berat badan, microtoise untuk mengukur tinggi badan, alat tulis seperti pensil, pulpen, penghapus, dan alas 
kertas. Data yang digunakan yaitu data diperoleh dari hasil kuesioner yang diberikan kepada subjek yang memenuhi kriteria inklusi.

\section{III.HASIL PENELITIAN}

Tabel 1

Karakteristik Subjek Penelitian $(\mathrm{n}=31)$

\begin{tabular}{lccc}
\hline Uraian & Rerata & SB & Rentangan \\
& & & \\
\hline Umur (th) & 37,26 & 9,50 & $22-55$ \\
Berat badan & 61,45 & 9,12 & $45,60 \quad-$ \\
$(\mathrm{kg})$ & & & 79,80 \\
& & & \\
IMT (kg/m $\left.{ }^{2}\right)$ & 164,98 & 7,87 & $151-185$ \\
$\begin{array}{l}\text { Pengalaman } \\
\text { kerja (th) }\end{array}$ & 14,71 & $9,78$. & $3-37$ \\
\end{tabular}

Berdasarkan Tabel 1 didapatkan bahwa variasi umur karyawan antara $22-55$ tahun dengan rerata $37,36 \pm 9,50$ tahun. Berat badan bervariasi antara 45,60 - 79,80 $\mathrm{kg}$ dengan rerata $61,45 \pm 9,12 \mathrm{~kg}$. Tinggi badan bervariasi antara $151-185 \mathrm{~cm}$ dengan rerata $164,98 \pm 7,87 \mathrm{~cm}$. Indeks
Massa Tubuh bervariasi antara 17,81 34,99 dengan rerata $23,14 \pm 4,10$. Pengalaman kerja bervariasi antara $3-37$ tahun dengan rerata $14,71 \pm 9,78$.

Uji korelasi dilakukan dengan uji Pearson dengan menghubungkan data kelelahan dan kemampuan kerja yang berdistribusi normal. Hasil analisis disajikan pada Tabel 2.

Tabel 2. Uji Korelasi Data Kelelahan dan Kemampuan Kerja

\begin{tabular}{ccc}
\hline & Skor WAI \\
\hline Skor kelelahan & $\mathrm{r}$ & $-0,450$ \\
& $\mathrm{p}$ & 0,011 \\
& $\mathrm{n}$ & 31 \\
\hline
\end{tabular}

*data bermakna signifikan dengan $\mathrm{p}<0,05$

Tabel 2 menunjukkan hubungan kelelahan dengan kemampuan kerja. Analisis kemaknaan dengan uji Pearson menunjukkan bahwa nilai $\mathrm{r}=-0,450$ dan nilai $\mathrm{p}=0,011$. Nilai $\mathrm{p}=0,011$ menunjukkan bahwa terdapat hubungan yang bermakna antara kelelahan dengan kemampuan kerja dimana nilai $p<0,05$. Nilai 
korelasi 0,450 menunjukkan adanya korelasi yang sedang sedangkan nilai min (-) menunjukkan adanya hubungan yang berlawanan arah (berbanding terbalik) antar variabel, yaitu semakin besar tingkat kelelahan semakin kecil skor kemampuan kerja subjek, begitupun sebaliknya. Namun hubungannya tergolong sedang.

\section{IV.PEMBAHASAN}

Variasi umur karyawan antara 22 55 tahun dengan rerata $37,36 \pm 9,50$ tahun. Dalam penelitian ini umur karyawan tergolong umur yang produktif dan masih dalam batas usia kerja, dimana batas usia kerja yang berlaku di Indonesia $15-64$ tahun. Rentangan umur pada subjek penelitian cukup lebar, namun jika dilihat dari jenis pekerjaan yang dilakukan, karyawan di bidang housekeeping ini membutuhkan usia pekerja yang produktif mengingat pekerjaan karyawan merupakan pekerjaan mental dan fisik yang banyak memerlukan kesiapan mental dan fisik. Kapasitas fisik seseorang berbanding lurus dengan umur tertentu dan puncaknya pada umur rata-rata 25 tahun, dan mengalami penurunan pada umur lebih dari 45 tahun (Gobel \& Zwick, 2009). Selain mempengaruhi skor kelelahan umur juga mempengaruhi kemampuan kerja. Selain itu, umur juga berhubungan dengan kemampuan pada tenaga kerja (Handari-Adiputra, 2013). Dengan bertambahnya umur, yaitu setelah melewati 30 tahun, fungsi fisiologis organ tubuh, seperti kapasitas daya tahan otot, fungsi paru dan denyut jantung berkurang $1 \%$ setiap tahunnya.

Hal ini penting karena karyawan housekeeping merupakan suatu ikon yang dapat meningkatkan kualitas hotel di bidang pelayanan yang diberikan. Secara tidak langsung hal ini dapat meningkatkan pendapatan perkapita bagi pihak hotel. Housekeeping memberikan pelayanan terhadap kelancaran, kesiapan dan 
pemeliharaan kamar tamu dan fasilitas lainnya. Karyawan housekeeping diwajibkan untuk perduli terhadap kenyamanan tamu dan menindaklanjuti segala perbaikan yang diperlukan. Umur sangat mempengaruhi kerja otot fisik, semakin tua usia seseorang maka akan semakin cepat mengalami kelelahan atau gangguan kesehatan (Widyasari, 2010).

Variasi berat badan karyawan antara $45,60-79,80 \mathrm{~kg}$ dengan rerata $61,45 \pm 9,12$ $\mathrm{kg}$ dan tinggi badan antara $151-185 \mathrm{~cm}$ dengan rerata $164,98 \pm 7,87 \mathrm{~cm}$. Berat badan dan tinggi badan digunakan untuk menentukan Indeks Massa Tubuh (IMT). Rerata IMT pada karyawan housekeeping hotel bintang tiga di Denpasar adalah 23,14 $\pm 4,10 \mathrm{~kg} / \mathrm{m}^{2}$, ini tergolong berat badan berlebih dimana IMT untuk orang Asia dikatakan normal jika berada pada rentang $18,5-22,9 \mathrm{~kg} / \mathrm{m}^{2}$.

IMT menunjukkan status gizi karyawan, IMT yang normal menunjukkan status gizi karyawan sudah sesuai dengan kebutuhan energi yang diperlukan untuk melakukan aktivitas (Handari-Adiputra, 2013). Status gizi juga menentukan kesehatan jasmani karyawan. Bila status gizi pekerja kurang atau buruk dan berlebih, akan berpengaruh langsung pada produktivitas, akibat daya tahan kerja menurun. Status gizi, dinyatakan memiliki hubungan yang bermakna dengan kelelahan. Semakin buruk status gizi semakin buruk tingkat kelelahannya, namun hubungan yang ditemukan tergolong lemah (Trisnawati, 2012).

Variasi pengalaman kerja karyawan antara $3-37$ tahun dengan rerata $14,71 \pm$ 9,78 tahun. Rentangan pengalaman pada subjek yang didapat cukup lebar. Dari hasil penelitian yang dilakukan oleh Mentari dkk. (2012) mengatakan bahwa kebanyakan orang yang telah bekerja di atas 10 tahun lebih cepat mengalami kelelahan dibandingkan dengan orang yang bekerja di 
bawah 10 tahun. selain itu, dinyatakan bahwa tingkat kelelahan lebih tinggi dialami oleh tenaga kerja dengan masa kerja yang lebih lama (Mentari, dkk., 2012). Makin lama ia bekerja, maka perasaan jenuh akibat pekerjaan yang monoton tersebut akan berpengaruh terhadap tingkat kelelahan yang dialaminya. Kelelahan yang terus-menerus akan berpengaruh pada kemampuan kerjanya.

\section{SIMPULAN}

Dalam penelitian ini disimpulkan bahwa terdapat hubungan antara kelelahan dan kemampuan kerja karyawan hotel pada bagian housekeeping yang ditunjukkan dengan hubungan berlawanan arah (berbanding terbalik) yaitu semakin besar tingkat kelelahan, semakin kecil skor WAI, begitupun sebaliknya.

\section{DAFTAR PUSTAKA}

Fernandes, C., Pereira, A., Haja, P.B., Amaral, V., Author, C.S.F. 2013. Age and Gender Differences in Work Ability Among Industri Worker: The Foundation For Safety Intervention Design. Safety Science Monitor. 17(8).

Gobel, C. and Zwick, T. 2009. Age and Productivity - Evidence from Linked Employer Employee Data: LudwigMaximilians-University

Munich.

Handari-Adiputra, L. M. I. S. 2013. Ergopsikofisiologi Menurunkan Respon Fisiologis, Meningkatkan Kesigapan, Kemampuan Kerja, dan Work Engagement Karyawan Bagian Akutansi Hotel Bali Hyyat Di Denpasar. (disertasi). Denpasar: Universitas Udayana.

Ilmarinen, J. 2012. Promoting Active Aging In the Work Place. European Agency for Safety and Health at Work. 
Mentari, A., Kalsum., Salmah, U. 2012.

Hubungan Karakteristik Pekerja Dan

Cara Kerja Dengan Kelelahan Kerja

Pada Pemanen Kelapa Sawit Di Pt.

Perkebunan Nusantara Iv (Persero)

Unit Usaha Adolina Tahun 2012.

Syahdianto., Jootje, M.L., Paul, A.T.,

Kawatu., Nancy, S.H., Molanda. 2012.

Hubungan Antara Stress Kerja Dengan

Tingkat Kelelahan Kerja Pada Pekerja

Lapangan Bagian Produksi PT. J

Resources Bolaang Mongondow.

Susetyo, J., Oesman, T.I., Sudharman, S.T. 2012. Pengaruh Shift Kerja Terhadap Kelelahan Karyawan dengan Metode Bourdon Wiersma dan 30 Item of Rating Scale. Jurnal Teknologi, 5 (1):32-39.

Trisnawati, E. 2012. Kualitas Tidur, Status

Gizi dan Kelelahan Kerja Pada Pekerja Wanita dengan Peran Ganda.

Vasconcelos, S.P., Fischer, F.M., Rels, A.O.A., Moreno, C.R.C. 2011. Factor
Associated With Work Ability and Perception of Fatigue Among Nursing Personnel from Amazonia. 2011.

Widyasari, J. K. 2010. Hubungan Antara Kelelahan Kerja dengan Stres Kerja Pada Perawat di Rumah Sakit Islam Yarsis Surakarta. (skripsi). Surakarta: Universitas Sebelas Maret. 